Proceedings of the 2011 Winter Simulation Conference

S. Jain, R.R. Creasey, J. Himmelspach, K.P. White, and M. Fu, eds.

\title{
LEARNING BY GAMING: SUPPLY CHAIN APPLICATION
}

\author{
Ayman Tobail \\ John Crowe \\ Amr Arisha \\ Dublin Institute of Technology (DIT) \\ 3S Group, College of Business \\ Aungier Street, Dublin 2, IRELAND
}

\begin{abstract}
Today's third level students are of a virtual generation, where online interactive multi-player games, virtual reality and simulations are a part of everyday life, making gaming and simulation a very important catalyst in the learning process. Teaching methods have to be more innovative to help students understand the complexity of decisions within dynamic supply chain environment. Interactive simulation games have the potential to be an efficient and enjoyable means of learning. A serious interactive business game, Automobile Supply Chain Management Game (AUSUM), has been introduced in this paper. Using theories learnt in class as a knowledge base, participants have to develop effective supply chain partnership strategy to enhance their supply chain networks. Deploying the game over the web encourages student interaction and group work. Most importantly the game will enable students to fundamentally grasp the impact of strategic decisions on other parts and players of the supply chain network.
\end{abstract}

\section{INTRODUCTION}

Ever since the introduction of a Simulation and Process Modeling module to the B.Sc. in supply chain management (SCM) at Dublin Institute of Technology (DIT) in 2008, there has been very positive feedback from students relating to how effective simulation modeling was in helping them get a better understanding of the dynamic nature of supply chains. The central theme of this paper is to develop an interactive supply chain serious game that can aid in teaching and training various concepts in SCM.

As a management philosophy, SCM is a vast concept, with many interpretations and definitions. Although the management concept itself was only introduced in early 1980 by Oliver and Webber, cited in Jüttner et al. (2007), it was not until the mid-1990's that it came to prominence on a global basis. SCM can be defined as the strategic management of upstream (suppliers) and downstream (customers) relationships in order to create enhanced value to the final consumer at less cost to the supply chain as a whole (Christopher 1998). At its basic level a supply chain is made up of multiple actors, multiple flows of items, information and finances and is sometimes described as looking like an 'uprooted tree'(Lambert and Pohlen 2001). Supply chains are very dynamic, each network node has its own customers' and suppliers' management strategies, partnerships, demand arrival process and demand forecast methods, inventory control policies and items mixture (Longo and Mirabelli 2008), with many challenges to overcome including: complexity, uncertainty, risk, visibility, collaboration, cost and sustainability to name a few. Most importantly, educating both SCM professionals and SCM students alike to fully understand the dynamics of the supply chain can be difficult. Textbooks, case studies and the traditional class lecture alone are an adequate foundation in helping students understand the fundamental concepts of SCM, but fail in highlighting the bigger picture of the supply chain and the strategic decisions that need to be made. In this environment it is hard for students to see things from a manager's perspective, where decisions made 
have real and costly consequences. The use of business games in lectures and computer labs is another pedagogical option which helps in understanding the theories learned in class and also put ideas into action in an enjoyable and interactive way (Mustafee and Katsaliaki 2010).

Using simulation technologies has been proven to be an excellent tool for modeling complex environments (Arisha and Young 2004). It is seen as a competent means of analyzing complex systems, allowing the changes and effects of processes to be understood and predicted more easily (Ismail, Abohamad, and Arisha 2010). The capabilities of simulation software to replicate uncertainty are high, mainly through discrete event simulation as it is capable of manipulating the variability and uncertainty of a system (Mahfouz, Ali Hassan, and Arisha 2010). In spite of this, there have been very few examples of SCM simulation games being used in education. The most popular being the beer game introduced by MIT in 1960 as an exercise in industrial dynamics (Iyer, Seshadri, and Vasher 2009). The use of web-enabling technologies can also be used as a powerful educational tool in SCM to encourage collaborative learning. The recent emergence of online technologies such as social networking reflects the potential improvements in interaction between students that can be made through the use of high-quality virtual environments (Davis, Gottschalk, and Davis 2007). It is argued that utilizing web technology is an obvious decision when implementing new study materials to liven up lectures (Syrjakow, Berdux, and Szczerbicka 2000). Web-based education games also have the advantage of being cheaper than expensive simulation software and give students online access outside of the classroom (Tobail, Crowe, and Arisha 2010).

The central theme of this paper is to develop an interactive web-enabled SCM game that students can use not only in the transfer of theory into practical knowledge, but also to aid them in fully understanding the complex and often costly decisions they will have to make as the next generation of SCM decision makers. Section 2 will give a background on the education technologies that are traditionally used to teach SCM and also introduce novel approaches to SCM learning that will aid students. An outline of the game objectives will then be given in Section 3 before an in-depth description of the game framework is given in Section 4. The design of the game will then be reviewed in Section 5, followed by an analysis of the teaching process from a student perspective in Section 6. To conclude, the outcomes of the game development will be discussed and the future direction of the game will be highlighted.

\section{SUPPLY CHAIN MANAGEMENT TEACHING TECHNOLOGIES}

The iterative nature of the learning process necessitates an ongoing refinement of a conceptualizeconstruct-identify pattern, with dialogue between the teacher and student playing an essential role in each stage (Fowler and Mayes 2000). In a typical SCM degree, the conceptualize-construct-identify process focuses on four core areas: material flow (e.g., inventory management), information flow (e.g., information management), capital flow (e.g., financial accounting), and management (e.g., project management) (DIT, 2011). Each of these areas incorporates many different academic disciplines and modules that require different knowledge and skill capabilities. Traditionally, when teaching business modules, the learning process was limited to transferring the necessary dialogue through teaching technologies of the time such as, the class lecture, textbooks, overhead projections, role play, case studies and journal articles (Ruben 1999). The ability to conceptually identify the dynamic nature of SCM and construct a strategic understanding of the decision making process is very difficult to achieve through such technologies alone. Moreover, the ability for students to visualize the importance, relationship, or links between degree modules and SCM decision making processes are also restricted. Simulation games have huge potential in being a very effective tool in achieving this goal.

Although using simulation games as a method of teaching is not a new concept, particularly in medical, military and aviation education (Murphy et al. 2011), it is growing rapidly in many other academic disciplines. The reasoning for such growth lies with simulations' potential to create clinical experiences that closely mimic the real life scenarios of a system (Zhang, Thompson, and Miller 2011). Whether simulating medical procedures without doing harm to a patient, or simulating a SCM concept without the costly change in business strategy, simulation is a powerful learning aid. There have been several examples of gaming and simulation theory being used in SCM. Some academics say that the medium of games 
have been under-utilized by educators, with institutes focusing on negative social consequences while ignoring the important potential of gaming and simulation as teaching aids (Squire 2003). There have been some aspects of the supply chain utilized through simulation games since the beer games introduction, but the potential has never fully been capitalized on. Games such as van der Zee and Slomp's assembly line simulation game (2009), and the activity-based-costing (ABC) flash simulator game developed by McKee and Lantz (2009), although very effective in visualizing and simulating the fields of production processes, ordering and costing, do not yield the scope in incorporating all areas of a supply chain. An attempt to simulate whole supply chain operations can be seen in the blood supply game (Mustafee and Katsaliaki 2010). Using the framework of the beer game, the blood supply game incorporates the movement of blood from the donor (supplier) right through to the patient (end user) and all material and information flows. Although the game gives students the opportunity to develop decision making skills and play the role of manager within the blood supply chain, it is still relatively small in scope, with first tier supply chain partners only. There is also limited interaction between players, a dimension that can be effectively executed through web-enabled technologies.

Studies suggest that online videogames are excellent educational tools that encourage knowledge acquisition and cognitive skills development through online group interaction and collaborative learning (Zea et al. 2009). Although the field of web-based simulation was first introduced by Fishwick (1996), the concept is said to be as old as the Web itself (Reichenthal 2002). In his paper, Fishwick formed an introductory overview of web-based simulation, to be used as a backdrop to a more formal discussion, with the objective of potentially forming a new simulation track. This in-turn, gave rise to a new era in simulation study and research into the field grew rapidly, but despite such a promising start, the number of real applications in the field, including web-enabled simulation games, is relatively small (Wiedemann 2001). This novel approach to education is commonly known as web-based learning and is an eLearning technique that has made the learning process more accessible by stretching spatial and temporal barriers (Khalifa and Lam 2002).

Computerized frameworks for simulation-based learning should be focused and directed towards clearly defined and pedagogical tasks that can facilitate the acquisition of decision making skills (Atolagbe, Hlupic, and Taylor 2001). From the review of current teaching technologies, there is a need for the development of a web-enabled, interactive, multi-echelon SCM game that will mimic the real life scenarios supply chain graduates will face when they are managers. The remainder of this paper will describe the development of a framework for an Interactive Automobile Supply Chain Management Game, or AUSUM for short.

\section{AUSUM GAME OBJECTIVES}

Although the core foundations of the AUSUM game framework are simulation based; its main objective is to move beyond the parameters of simulation and create a game that emphasizes the necessity for the player to be creative in acting, deciding and solving problems (Brougère 1999). Acknowledging the steps to creating a successful game by Pivec, Dziabenko, and Schinnerl, (2003), the main objectives of AUSUM game are:

- Develop students' understanding of supply chain complexity and dynamics through immersing them in a model supply chain world.

- Increase the capability of students to make suitable decisions in different challenging situations under different scenarios, in a time-based environment with level advancement capabilities.

- Encourage students to practice group work and collaboration through web-based capabilities.

- Improve the management skills of students by measuring their performance and assign goals for them to achieve.

Integrating simulation within a game makes the educational tool more enjoyable and attractive, increasing the probability that students will play the game for longer periods, which in turn will make the student gain more knowledge. Using different supply chain scenarios, the game aims to help students ap- 
ply the theories studied in the classroom and experience the impact of their decisions, which increases knowledge retention. The student can communicate with other students in the game and share information to decrease decision making risk, which enables the information-sharing concept in risk mitigation.

\section{AUSUM GAME FRAMEWORK}

Employing simulation in SCM education involves many challenges due to the complexity and dynamics related to this field. Simplifying the method of introducing the field of SCM to beginners to guarantee an effective way in delivering supply chain concepts and theories, requires an integration of different technologies into an interactive learning framework (Figure 1). The graphical user interface block is designed to collect data and commands from the user in a friendly environment, where the controlling agent sends the state of the user to the simulation model according to predefined rules in communication between the client and the server that runs the simulation model. The optimization agent finds optimal or near optimal solutions subject to the constraints stated in the case. Using genetic algorithms, the optimization process iterates against set rules in order to converge to a solution. Iterations will include a comparative analysis between current state of the user with the previous saved states in the rule-base. The recommended solution will be communicated through to the users in order to mitigate risks due to his/her decisions.

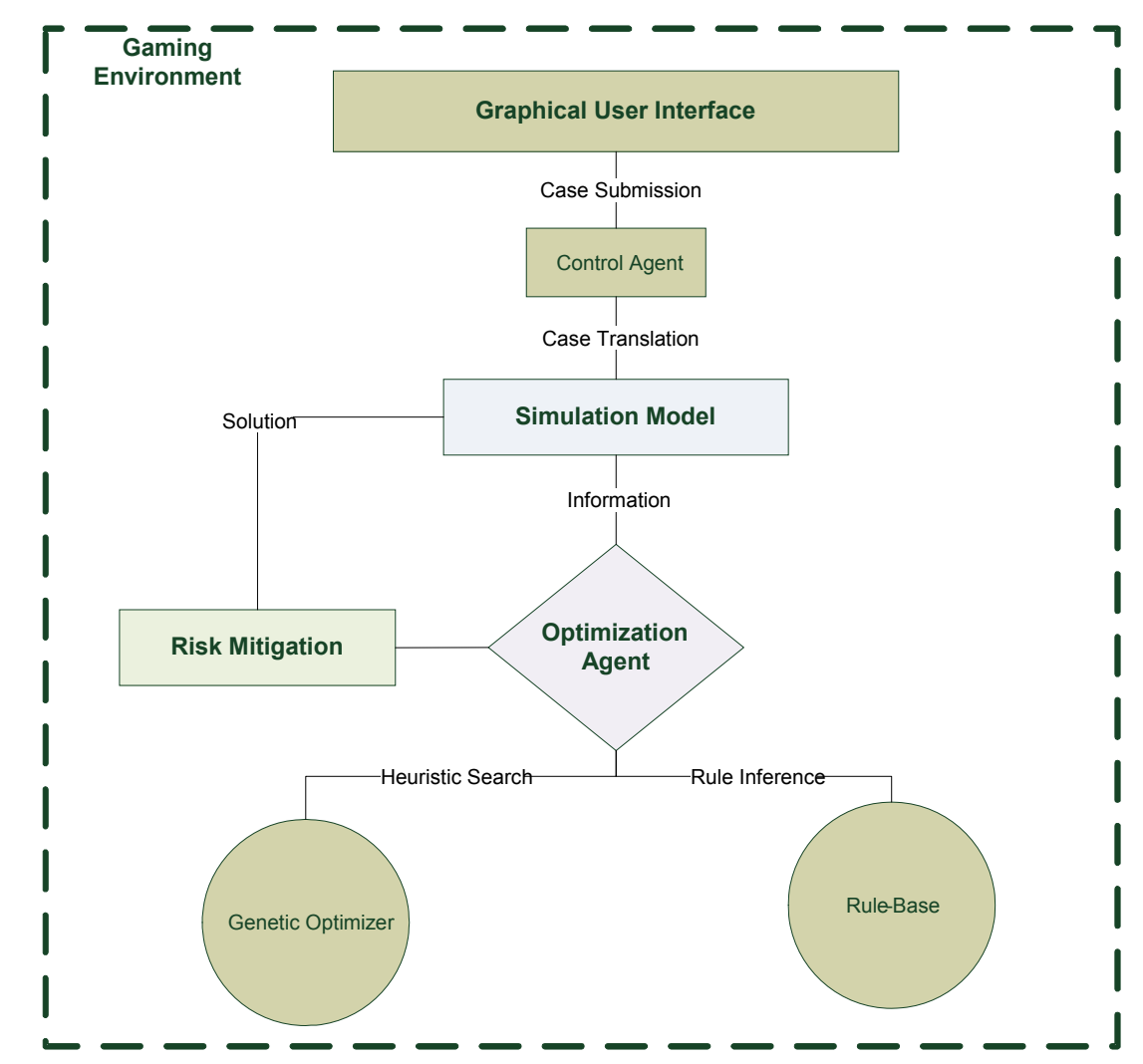

Figure 1: AUSUM game framework

Simulation modeling and technology are effectively used in many business domains and proven to be robust when it comes to examining the impact of various scenarios on performance outcomes. This encourages students and trainees to engage in new innovative ways of thinking when it comes to managing supply chains. Applying interactive game technology incorporated with simulation seems to be the way forward to attract managers and learners in the domain of supply chain. Participants in the game environ- 
ment will find it interesting to use a friendly graphical user interface environment to manage their supply chains than the traditional ways in delivering the same concepts.

In addition, the competitive challenges in the game environment proposed in this framework encourage participants to engage for longer periods which increase time spent learning and engaging in building knowledge in the area. To develop certain interaction skills in the students through collaborative engagement, web-enabling technologies have been used. This engagement helps in developing human soft skills like group work and communication skills. From the perspective of SCM, building the game as a webbased tool increased the potential to apply SCM and risk management theories such as, influence of information sharing in risk mitigation and collaboration management. The accessibility of the simulation model increases with the integration of web technology, where the trainee can access the model with the last saved state through the web from anywhere with online access.

\subsection{Framework Structure}

The framework has been built based on three layers; interface layer, communication layer and the core engine layer (Figure 2).

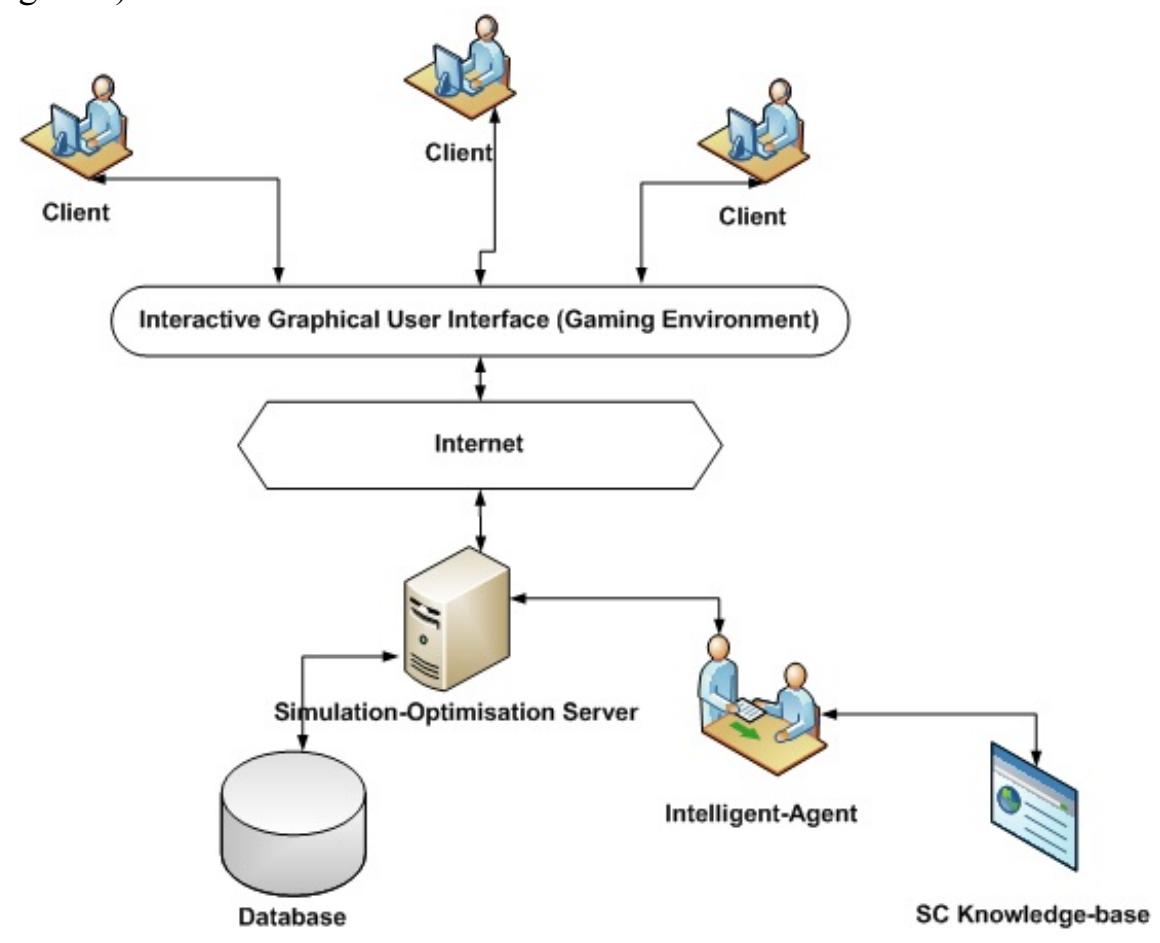

Figure 2: Three layers of AUSUM framework

\subsubsection{The Interface Layer}

This layer comprises the graphical user interface and simple communication and calculation engine. This layer represents the client layer. It has the client software that is running on the user machine. High userfriendly specifications, functionality and usability have been taken into account while designing this client software. Behind this interface is a communication engine that runs while the user works on the interface. This engine is responsible for communication with the main server. To achieve this mission some effort of calculations, filtration and data encoding are needed. The part of the tool running on the client machine has been built as a thin client agent to save the capacity and processing power of the client machine. 


\subsubsection{Internet and Communication Layer}

The function of this layer is to act as a coupling point between the client environment and the server and core engine of the tool. The protocol used in communication is the TCP/IP internet communication protocol. Encoding and communication synchronization from the client layer are executed by the communication module embedded in the client side software. On the other side, the server engine communicates with the clients in the same way, using the rules and modules developed on the server for this purpose.

\subsubsection{The Server and Core Engine Layer}

This layer comprises of four components; simulation and optimization server, database management system, knowledge base and intelligent agent.

- Simulation-optimization server - main task of this server is to manage the simulation model of the supply chain and the communication between the client and the server. The optimization module has been engaged to the simulation server to produce potential optimum solutions to help users in the decision making stage.

- Database management system - all data and information related to the users and their current state or communication state are stored in the database to be used later in the analysis stage. The user login and definition information are also stored in the database to manage the security system.

- Knowledge base - certain supply chain situations and related decisions taken by the users or recommended by the optimization engine are used in the knowledge base to be used as case based reasoning in the similar situations.

- Intelligent agent - the intelligent agent is responsible for extracting the cases to be stored in the knowledge base and re-use them in a similar situation, after recognizing the similar situations.

\section{AUSUM DESIGN MODEL}

The automobile industry was selected for the case-study. Extensive research was done to identify the factors and ratios within the complex automobile supply chains. There are five main roles for any user to play; Supplier, Manufacturer, Logistics Provider, Distributor and Retailer. The hidden role -administrator role- is designed to enable the administrator of the game to control, apply scenarios, gather and analyze player decisions and interaction data and apply different benchmarks (Figure 3). The administrator role can be executed by the SCM lecturer for example.

Each role has its own interface, inputs, outputs, tools and functions (Figure 4). The tool is designed to be published over the web to be used through a login website to broaden the accessibility of the model. Different features have been embedded in the game implementation to enable the user to communicate with other users and choose partners to be part of the user's supply chain, which apply the concept of collaboration and information sharing.

Goals and key performance measures have been extracted to reflect user performance and encourage the user to work harder towards achieving certain goals. These features make the tool more attractive and increase the potential of usability. Supply chain decisions and dynamics are very challenging areas in SCM. An optimization engine has been built to support the user in decision-making. The required data and information for the optimizer is collected on a real-time basis, while the user is taking actions.

Using the friendly graphical user interface, the student can manage his company; if the student plays a supplier role then using certain icons the student can buy goods from other suppliers, receive them and store them in warehouses, receive orders from manufacturers and ship goods to them. Through the performance indicators and amount of money earned, the user's performance is measured and enables moving from one level to another. The lecturer can check students interactions and how they deal with decision making situations, to measure their learning from lectures. This allows the lecturer to control the game and apply different scenarios using the administrator's control panel. 


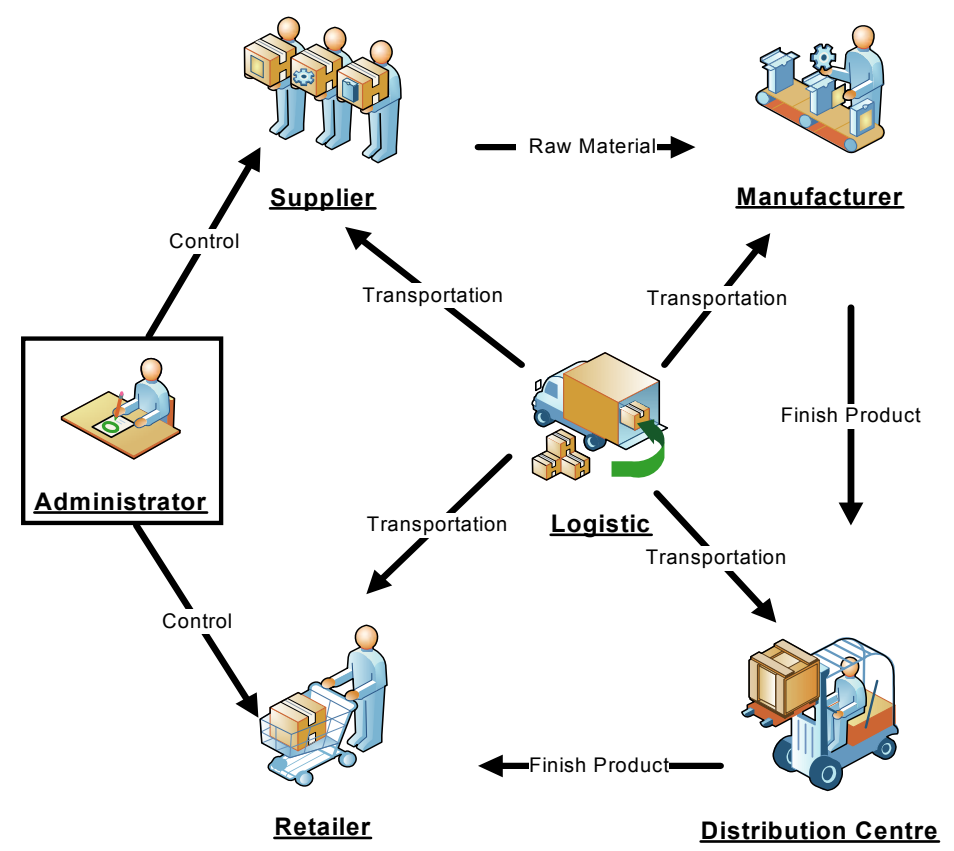

Figure 3: Administrator role

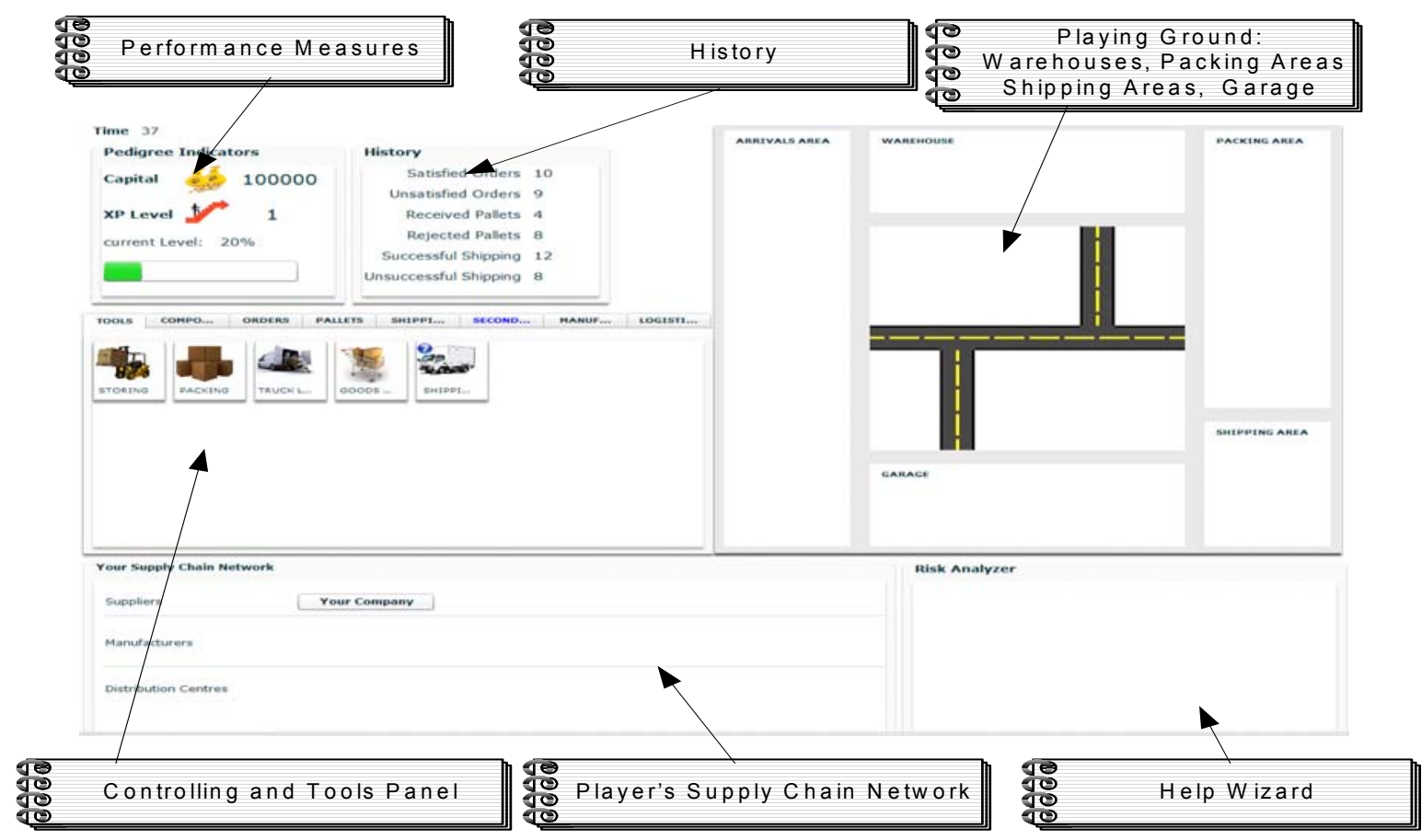

Figure 4: AUSUM interface example - supplier role

\section{TEACHING PROCESS}

To progress, each player will have to decide from several management scenarios including: what supply chain function to choose. how to build their company; which assets to buy; and calculate order quantities. Accurate decision making capabilities are required in this stage, as capital is limited and needs to be used 
strategically and not wasted. To build their supply chain, the student can communicate with other players (companies' owners) in the game and ask them to be partners. This improves the students' knowledge of negotiations and making contracts. Based on Toyota's North American Supply Chain (Iyer, Seshadri, and Vasher 2009), and scaled approximately to a ratio of 1:50, to initiate a full working supply chain, a student will have to join a supply network that is at minimum 6 suppliers; 1 Manufacturer; 8 Logistics providers; 1 Distributor; and 4 Dealerships. The scale is based on supplier and dealership figures, manufacturer and distributor numbers are rounded up to 1 each (from 0.18 and 0.06 respectively), there was also no accurate figures available on logistics providers, therefore the figure of 8 has been calculated as the best-fit number to operate the supply chain effectively.

Once the student has enough partners, the business process begins. The student can receive orders from supply chain partners and will have to manage the fulfillment of these orders to the optimum level, which includes on-time delivery, correct order quantities and the most efficient costs. Keeping aligned to the core parameters of SCM education discussed in Section 2 (i.e., material, capital and information flows), the game framework is built upon fundamental supply chain concepts, equations and theories that the students themselves have learned in the class lecture.

Inventory management, which is a crucial decision making process of SCM, starts when the student tries to source suppliers and decide to order from them. Different ordering policies can be followed in this stage. All ordering policies are based on the principles of the economic order quantity (EOQ) (Erlenkotter 1990), which calculates the optimum order quantity required to balance holding and ordering costs and minimize total costs. Mathematically, the structure of the EOQ (1), Ordering Costs $\left(C_{O}\right)$ (2), Holding Costs $\left(C_{H}\right)(3)$, are given in Equations 1 to 3, and are measured in generic units.

if

$$
E O Q=\sqrt{\frac{2 D * C_{O}}{C_{H}}}
$$

and

$$
C_{O}=C_{L}+C_{R}
$$

$$
C_{H}=C_{C}+C_{S}+C_{D}+C_{M}+C_{A d}
$$

Where $\mathrm{D}=$ Annual Demand, $C_{L}=$ Cost of labor, $C_{R}=$ Cost of resources, $C_{C}=$ Cost of capital, $C_{S}=$ Cost of storage, $C_{D}=$ Cost of loss and damages, $C_{M}=$ Cost of moving inventory, and $C_{A d}=$ Cost of administration.

To ensure orders are placed at the correct point of time to avoid the possibility of either stockout (lost sale costs) or over-stocked inventory (storage, obsolete and perishable costs), the optimum calculation for the reorder point (ROP) is required (Liao and Shyu 1991). Assuming the receipt of an order is instant and demand is constant, a lead-time for delivery is required to calculate the ROP (Equation 4a), which is the demand per day $(d)$ (Equation 5) times the lead-time (LT) in days. If this assumption cannot be made a safety stock (SS) is normally required to allow for uneven demand (Equation 4b). Using normal distributed probability $(Z)$ with $95 \%$ confidence set as a service level, the $S S$ is calculated using Equation 6.

$$
R O P=d * L T
$$

or

$$
R O P=d * L T+S S
$$

where

$$
d=\frac{D}{\text { Numberofworkingdaysperyear }}
$$

and

$$
\begin{gathered}
S S=Z * \sigma * \sqrt{L T} \\
Z=\frac{x-\mu}{\sigma}
\end{gathered}
$$


Where $\sigma=$ standard deviation, $x=$ estimated demand during $L T$, and $\mu=$ average demand during $L T$. The game administrator also uses Equation 7 when adding risk to delivery lead-times including bad weather, road accidents, damaged goods and rush hour traffic.

Periodical demand $(D)$ is also controlled by the games administrator. Because the game is played with limited historical data, simple exponential smoothing (Gardner Jr. 1985) is used when forecasting $D$. This is another mathematical calculation that business students will be familiar with and can use to forecast what $D$ will be before the administrator issues customer demand per period $(n)$. The new demand forecast $\left(D_{t}\right)$ is calculated using Equation 8.

$$
D_{t}=D_{t-1}+\propto\left(A_{t-1}-D_{t-1}\right)
$$

Where $D_{t-1}=$ previous periods forecast, $\propto=$ smoothing constant $(0 \leq \alpha \leq 1)$, and $A_{t-1}=$ previous periods actual demand. In the game, the $\propto$ smoothing constant is set at 0.8 as the most recent demand data is given more weight. To assist the student in predicting their demand patterns, the game also highlights the average forecast error for each period. Mean Absolute Percentage Error (MAPE) (Goodwin and Lawton 1999) is used to calculate the mean absolute difference between the forecasted and actual values of demand, expressed as a value of actual demand (Equation 9). Students can use MAPE to limit the risk involved in matching supply and demand, and also when calculating new $\propto$ weights, if they feel the computers weight is not accurate.

$$
M A P E=\frac{\sum_{i-1}^{n} 100 \mid \text { Actual }_{i}-\text { Forecast }_{i} \mid / \text { Actual }_{i}}{n}
$$

Students' decision making capabilities when allocating warehouse space in accordance to inventory policies will also be a factor on how successful they are during the game. Similar to incurring costs by under or over ordering inventory, these costs can be incurred by under or over utilizing storage capacity. Using the calculations for productivity = output/input (Equation 10), the game allows students to monitor how effectively they are using their warehouse space. For example, $50 \%$ pallet space usage per month would suggest that the student has too much storage capacity or not enough orders. Conversely, if productivity for storage was $100 \%$ spaces used per month there is a chance the student needs more capacity and has probably lost sales orders due to storage constraints.

To deliver the orders, students need to make decisions on which logistics providers (3PL) to use. Equation 10 is also very effective in measuring the performance of 3PL's delivery time productivity. When order terms (delivery time, rate, etc.) are agreed to, the shipping process starts. According to satisfied or backlogged orders, the performance measures change to indicate the student's performance (Figure 5). This encourages the student to increase the management effort to get better results. These results are reflected on the server, and are available to the instructor for analysis. Not only the results, but also the student's decisions in different situations can be analyzed. This helps the instructor to monitor the amount of knowledge gained or used by the students while playing and also refine the game variables to generate different scenarios.

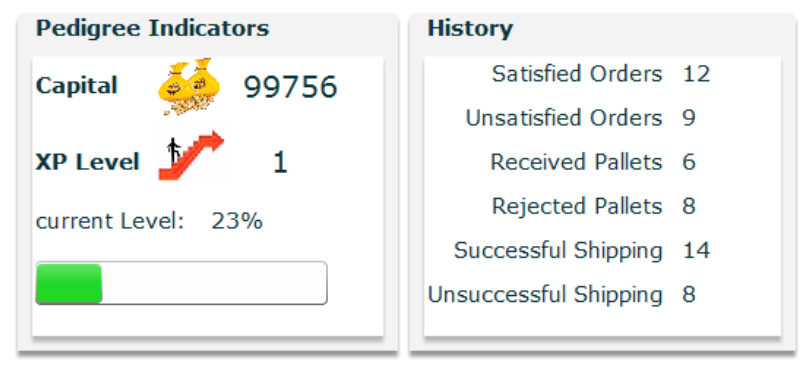

Figure 5: Graphical Interface to monitor performance during game

The instructor can also give the students feedback about their behavior to enhance their performance and knowledge revision. The proposed framework allows different supply and demand generation pat- 
terns to be applied and added to the engine of the game. Moreover, there is a suitable degree of flexibility in the graphic user interface and designed engine, allowing the change of existing functions or the addition of more functions and tools to increase the complexity of the model.

\section{CONCLUSION}

The dynamic nature of supply chains and the complexity in managing them are documented in many academic and professional articles incorporating many theories, concepts and scientific approaches. As a result, the study of SCM imposes considerable challenges in the learning process. Research has shown that today's students enjoy a virtual era, where the internet, through online multi-player games, virtual reality and social networking sites can potentially be an important technological catalyst in the learning process. Since the introduction of the Beer Game in 1960, the promising potential for using simulation game and web-enabled technologies in SCM education has never been reached.

Based on actual feedback given by SCM B.Sc. students, this paper presents a working framework for an automobile supply chain management (AUSUM) game. Acknowledging the virtual generation, AUSUM combines web-based simulation and game technologies to produce an interactive, engaging educational tool that creates an enjoyable productive learning environment. In AUSUM, participants mimic real life decision making processes by playing a role in the automobile supply chain. Every role has different decisions to make within the supply chain network, which creates a business vision for every player and a set of responsibilities. Collaboration is promoted within the game in order to assess the network coherence and its impact on overall performance. Participants will have a good opportunity to apply their learning outcomes in terms of decision and analysis of business situations. Through the administrator role, various supply chain scenarios can be applied, then participants' decisions can be collected for appraisal. An optimization module is incorporated in the simulation server in order to show potential optimum solutions which endorse students' understanding of the importance of decisions within SCM.

Most importantly the game will enable students to fundamentally grasp the impact of strategic decisions on other parts of the supply chain network.

The next stage in AUSUM development is a pilot run of the full game as part of the Simulation and Process Modeling module at DIT in the 2011/2012 academic year, during which its effectiveness in student learning processes will be analyzed and evaluated.

\section{ACKNOWLEDGEMENTS}

The authors wish to thank the Irish Research Council for Science, Engineering, and Technology (IRCSET) for contributing to the funding of this research project and also thank Anita Crowe for her support in the final editing of the paper.

\section{REFERENCES}

Arisha, A., and P. Young. 2004. "Intelligent Simulation-Based Lot Scheduling of Photolithography Toolsets in a Wafer Fabrication Facility." In Proceedings of the 2004 Winter Simulation Conference, edited by R. G. Ingalls, M. D. Rossetti, J. S. Smith, and B. A. Peters, 1935-1942. Piscataway, New Jersey: Institute of Electrical and Electronics Engineers, Inc.

Atolagbe, T., V. Hlupic, and S. J. E. Taylor. 2001. "Genisa: A Web-Based Interactive Learning Environment for Teaching Simulation Modeling." In Proceedings of the 2001 Winter Simulation Conference, edited by B. A. Peters, J. S. Smith, D. J. Medeiros, and M. W. Rohrer, 1605-1612. Piscataway, New Jersey: Institute of Electrical and Electronics Engineers, Inc.

Brougère, G. 1999. "Some Elements Relating to Children's Play and Adult Simulaton/Gaming." Simulation \& Gaming 30:134-146.

Christopher, M. 1998. Logistics and Supply Chain Management: Strategies for Reducing Cost and Improving Service. London: Financial Times Publishing. 
Davis, D. M., T. D. Gottschalk, and L. K. Davis. 2007. "High-Performance Computing Enables Simulations to Transform Education." In Proceedings of the 2007 Winter Simulation Conference, edited by S. G. Henderson, B. Biller, M.-H Hsieh, J. Shortle, J. D. Tew, and R. R. Barton, 2336-2343. Piscataway, New Jersey: Institute of Electrical and Electronics Engineers, Inc.

DIT. 2011. SCM Undergraduate Degree Modules [Online]. Accessed March 24. http://www.dit.ie/study/undergraduate/programmes/logisticsandsupplychainmanagementdt358/.

Erlenkotter, D. 1990. "Ford Whitman Harris and the Economic Order Quantity Model." Operations Research 38:937-946.

Fishwick, P. A. 1996. "Web-Based Simulation: Some Personal Observations." In Proceedings of the 1996 Winter Simulation Conference, edited by J. M. Charnes, D. J. Morrice, D. T. Brunner, and J. J. Swain, 772-779. Piscataway, New Jersey: Institute of Electrical and Electronics Engineers, Inc.

Fowler, C. H., and J. T. Mayes. 2000. "Learning Relationships from Theory to Design." Association of Learning Technology Journal 7:6-16.

Gardner Jr., E. S. 1985. "Exponential Smoothing: The State of the Art." Journal of Forecasting 4:1-28.

Goodwin, P., and R. Lawton. 1999. "On the Asymmetry of the Symmetric MAPE." International Journal of Forecasting 15:405-408.

Ismail, K., W. Abo-hamad, and A. Arisha. 2010. "Integrating Balanced Scorecard and Simulation Modeling to Improve Emergency Department Performance in Irish Hospitals." In Proceedings of the 2010 Winter Simulation Conference, edited by B. Johansson, S. Jain, J. Montoya-Torres, J. Hugan, and E. Yücesan, 2340-2351. Piscataway, New Jersey: Institute of Electrical and Electronics Engineers, Inc.

Iyer, A. V., S. Seshadri, and R. Vasher. 2009. Toyota Supply Chain Management, New York: McGrawHill.

Jüttner, U., M. Christopher, and S. Baker. 2007. "Demand Chain Management - Integrating Marketing and Supply Chain Management." Industrial Marketing Management 36, 377-392.

Khalifa, M., and R. Lam. 2002. "Web-Based Learning: Effects on Learning Process and Outcome." IEEE Transactions on Education 45:350-356.

Lambert, D., and T. Pohlen. 2001. "Supply Chain Metrics." International Journal of Logistics Management $12: 1-20$.

Liao, C. J., and C. H. Shyu. 1991. "An Analytical Determination Of Lead Time With Normal Demand." International Journal of Operations \& Production Management 11:72-78.

Longo, F., and G. Mirabelli. 2008. "An Advanced Supply Chain Management Tool based on Modeling and Simulation." Computers \& Industrial Engineering 54:570-588.

Mahfouz, A., S. Ali Hassan, and A. Arisha. 2010. "Practical Simulation Application: Evaluation of Process Control Parameters in Twisted-Pair Cables Manufacturing System." Simulation Modelling Practice and Theory 18:471-482.

McKee, J. A., and K. A. Lantz. 2009. "The ABC Simulator: A New Approach to Teaching Traditional Topics." Management Accounting Quarterly 10:28-33.

Murphy, S., I. Hartigan, N. Walshe, A. V. Flynn, and S. O'Brien. 2011. "Merging Problem-Based Learning and Simulation as an Innovative Pedagogy in Nurse Education." Clinical Simulation in Nursing 7:141-148.

Mustafee, N., and K. Katsaliaki. "The Blood Supply Game." In Proceedings of the 2010 Winter Simulation Conference, edited by B. Johansson, S. Jain, J. Montoya-Torres, J. Hugan, and E. Yücesan, 327338. Piscataway, New Jersey: Institute of Electrical and Electronics Engineers, Inc.

Pivec, M., O. Dziabenko, and Schinnerl, i. Aspects of game-based learning. 2003. Citeseer, 216-225.

Reichenthal, S. W. 2002. "Re-introducing Web-Based Simulation." In Proceedings of the 2002 Winter Simulation Conference, edited by E. Yücesan, C. H. Chen, J. L. Snowdon, and J. M. Charnes, 847852. Piscataway, New Jersey: Institute of Electrical and Electronics Engineers, Inc.

Ruben, B. 1999. "Simulations, Games, and Experience-Based Learning: The Quest for a New Paradigm for Teaching and Learning." Simulation \& Gaming 30:498-505. 
Squire, K. 2003. "Video Games in Education." International Journal of Intelligent Simulations and Games 2:49-62.

Syrjakow, M., J. Berdux, and H. Szczerbicka. 2000. "Interactive Web-Based Animations for Teaching and Learning." In Proceedings of the 2000 Winter Simulation Conference, edited by J. A. Joines, R. R. Barton, K. Kang, and P. A. Fishwick, 1651-1659. Piscataway, New Jersey: Institute of Electrical and Electronics Engineers, Inc.

Tobail, A., J. Crowe, and A. Arisha. 2010. "Web-Based Supply Chain Simulation: An Integrated Approach." In Proceedings of ICERI 2010, edited by L. G. Chova, D. M. Belenguer and I. C. Torres, 4729-4738. Madrid: International Association of Technology, Education and Development.

van der Zee, D. J., \& J. Slomp. 2009. "Simulation as a Tool for Gaming and Training in Operations Management - A Case Study." Journal of Simulation 3:17-28.

Wiedemann, T. 2001. "Simulation Application Service Providing (SIM-ASP)." In Proceedings of the 2001 Winter Simulation Conference, edited by B. A. Peters, J. S. Smith, D. J. Medeiros, and M. W. Rohrer, 623-628. Piscataway, New Jersey: Institute of Electrical and Electronics Engineers, Inc.

Zea, N. P., J. L. G. Sánchez, F. L. Gutiérrez, M. J. Cabrera, and P. Paderewski. 2009. "Design of Educational Multiplayer Videogames: A Vision from Collaborative Learning." Advances in Engineering Software 40:1251-1260.

Zhang, C., S. Thompson, and C. Miller, c. 2011. "A Review of Simulation-Based Interprofessional Education." Clinical Simulation in Nursing 7:117-126..

\section{AUTHOR BIOGRPAHIES}

AYMAN TOBAIL is a researcher in $3 \mathrm{~S}$ Group. He received his B.Sc. degree in Computer Engineering from Arab Academy for Science and Technology in 2002 with first class honors. He is currently working towards completing his PhD in Dublin Institute of Technology. Prior to this work, he had seven years of teaching experience in colleges of Engineering and Information Systems. He published several conference papers in the area of Innovation in Education and Simulation Applications in Supply Chain Management Education. His research interest is mainly in Simulation, Optimization, Artificial Intelligence and Web-Technologies. His email address is ayman.tobail@dit.ie.

JOHN CROWE is a researcher in the 3S Group. He joined the 3S group in 2009 with five years industry experience in logistics and inventory analysis. He received his B.Sc. degree specialized in Supply Chain Management from Dublin Institute of Technology (DIT). Mr. Crowe won few outstanding prizes during his study time in DIT. In 2009, John successfully won a two year research scholarship with the Irish Research Council for Science, Engineering and Technology (IRCSET). John has published several articles in innovation in education and simulation international conferences. His research interests include supply chain management, simulation modeling application in business process analysis and simulation/webbased learning and education. His email address is john.crowe@dit.ie.

AMR ARISHA is a 3S Group Director (Research unit in DIT specialized in Smart Sustainable Solutions for complex business processes). He taught in Dublin City University (DCU), Alexandria University, Arab Academy for Science and Technology and Maritime Transport, Dublin Institute of Technology (DIT). He is currently Head of Department of International Business, College of Business at DIT. Dr. Arisha has published over 20 journal and international conference articles in the area of decision support systems for complex business processes in both manufacturing and service sectors. His research includes Business Process Simulation, System dynamics, Optimization, and Operations Excellence applications in Supply Chain Management. Dr. Arisha is a PRINCE2-certified (project management), an accredited FAS trainer since 2005 and completed a higher certificate in training (teaching and learning) in 2007. He is also a chief examiner of Marketing Institute of Ireland (MII). Dr. Arisha has led many projects in the areas of Risk Assessment, Operations Excellence, Supply Chain Management and Capacity Planning in IntelIreland and other national and international organizations. His email address is: amr.arisha@dit.ie. 